\title{
Sobre o Estatuto Epistemológico da Racionalidade Econômica segundo Karl Popper
}

\section{Brena Paula Magno Fernandez}

Professora - Universidade Federal de Santa Catarina (UFSC) - Departamento de Economia e Relações Internacionais - Endereço: Campus Universitário de Trindade, Santa Catarina/SC - Brasil CEP: 88040-900 - E-mail: brena.fernandez@ufsc.br

\section{Duilio de Avila Bêrni}

Professor - Universidade Federal de Santa Catarina (UFSC) - Departamento de Economia e Relações Internacionais - Endereço: Campus Universitário de Trindade, Santa Catarina/SC - Brasil CEP: 88040-900 - E-mail: duilio.avila.berni@ufsc.br

Recebido em 21 de dezembro de 2012. Aceito em 17 de março de 2014.

\section{Resumo}

Três tipos de críticas são comumente levantadas contra a utilização do postulado da racionalidade na ciência econômica. A primeira delas associa-se ao argumento da circularidade, a segunda diz respeito à blindagem da teoria contra a refutação e a terceira - e mais importante delas - refere-se à inadequação empírica. O presente artigo busca encaminhar esta última, à luz do tratamento dado por Popper ao longo de sua carreira para a questão de qual seria o estatuto epistemológico do princípio da racionalidade nas teorias econômicas. Três possíveis respostas a esta questão são aqui examinadas, explicitando-se suas respectivas estruturas lógicas. A primeira delas propõe que o postulado da racionalidade desempenhe o papel de lei geral do comportamento humano. A segunda requer que ele funcione como um axioma da teoria. Finalmente, a terceira proposta sugere que o postulado da racionalidade seja entendido como regra metodológica. Conclui-se o artigo sugerindo que esta última solução satisfaz ao apelo que o tipo de crítica aqui examinada faz ao conceito de racionalidade. Não obstante, ao situar-se no contexto metateórico, o postulado da racionalidade mantém importância inegável na teoria econômica. Sem ele, não se disporia de instrumentos que conduzissem à seleção de dados empíricos voltados ao teste das teorias.

\section{Palavras-Chave}

Epistemologia da Economia, Karl Popper, Postulado da Racionalidade

\begin{abstract}
Three types of criticism are currently raised against the acceptance of the rationality principle in economic science. The first relates to the circularity of the reasoning, the second concerns the protection of the theory against refutation, and the third - the most relevant - concerns the empirical inadequacy of the concept. This article aims to discuss the last criticism, considering the work performed by Popper, in different moments of

- Os autores agradecem as críticas, comentários e sugestões de João Rogério Sanson, Vinícius Valent, bem como dos pareceristas anônimos da revista Estudos Econômicos. Qualquer imprecisão conceitual que porventura permaneça é, naturalmente, de nossa responsabilidade.
\end{abstract}


his career, devoted to determine the epistemological status of the rationality principle. There are three main possible answers to be examined below. The first suggests that this postulate be considered as a general law of human behavior. The second requires it to function as an axiom of the theory. Finally, the answer to the third criticism sees the rationality postulate as a methodological rule. The article is finished with a statement that the last solution is a good answer to the core of the above referred criticisms to the conventional concept of rationality. Therefore it is concluded that, as far as it is situated in a metatheoretical context, the rationality postulate embraces undeniable importance as a foundation of economic theory. Its absence or non-existence would imply the unavailability of instruments leading to the very selection of the empirical data designed to submit the theory to tests.

\section{Keywords}

Epistemology of the Economic Science, Karl Popper, Postulate of Rationality

\section{Introdução}

A teoria da escolha racional foi desenvolvida no século XX, de modo mais ou menos independente, por filósofos, economistas, matemáticos e estatísticos. O modelo de tomada de decisão racional pode ser aplicado a contextos diversos, que incluem, para além das quatro áreas recém-citadas, a gestão empresarial, a elaboração de políticas públicas, a análise das relações internacionais e mesmo a biologia evolucionista. Mas o que significa dizer que os agentes - isto é, entes que agem - o fazem racionalmente?

O denominador comum de todas essas possibilidades de aplicação do modelo é o tratamento teórico de sequências mentais formalizáveis que podem ser abstratamente consideradas. Uma das abordagens convencionais voltadas à descrição da decisão racional considera uma entidade (o agente) cujo comportamento resulta da interação entre seus desejos e crenças. ${ }^{1}$ As crenças nada mais são do que representações de conhecimento, ao passo que desejos resultam de estruturas que objetivam alcançar determinadas finalidades.

1 Ainda que considerando, no dizer de Weber, uma concepção de racionalidade instrumental (ação destinada a alcançar objetivos perfeitamente conhecidos), deve-se assinalar que não fazem parte da problemática selecionada para tratamento neste artigo as intermediações necessárias para a aceitação de limites ao próprio conhecimento. Neste caso, destacar-se-iam os conceitos de racionalidade processual e racionalidade expressiva. A primeira vê comportamentos humanos justificados por meio da adoção de regras práticas, ao passo que a segunda expressa valores e condicionantes individuais. 
O comportamento destes agentes norteia-se pelo que se convencionou chamar de postulado da racionalidade. Entende-se aqui razão como um estado mental que envolve dois polos. O primeiro centraliza os desejos e as crenças do agente: a crença que empreendendo a ação $A$ o agente $X$ satisfará o desejo Æ. No segundo polo localiza-se a percepção do agente sobre a situação na qual ele próprio se encontra num dado momento.

Formulado de outro modo, considere-se um agente (indivíduo, família, empresa, estado, ou mesmo um animal) que possui um conjunto de crenças e um conjunto de desejos. Diz-se que sua ação foi racional se resultou na escolha, entre as diversas opções de ação possíveis, daquela que, de acordo com suas crenças, lhe pareceu a mais adequada para a consecução de seus objetivos. Teorias que fazem uso do conceito de decisão racional pressupõem portanto agentes, crenças, desejos e resultados esperados, mesmo que não haja qualquer consciência por parte dos entes envolvidos com relação à racionalidade de suas ações.

Nesse contexto insere-se a definição de ciência econômica como voltada ao estudo do comportamento de agentes racionais, com uma peculiariedade adicional além daquelas já mencionadas. Também se considera como parte indissociável da racionalidade econômica a tentativa que o agente autointeressado faz de otimizar o resultado de suas ações. ${ }^{2}$ Tal concepção é bem conhecida e amplamente aceita pela corrente dominante em teoria econômica, sendo igualmente considerada pelo enfoque walrasiano, por Robbins, Mises, assim como por boa parte dos praticantes da teoria clássica dos jogos. De fato, de todas as chamadas ciências sociais e humanas, é a economia aquela que seleciona um postulado de racionalidade da ação dos agentes de modo a demarcar seu objeto. Contudo essa não é uma posição de consenso, uma vez que a utilização deste postulado na ciência econômica vem sofrendo ataques severos, provenientes das mais variadas frentes.

2 Cabe lembrar que essa racionalidade egoísta atribuída ao agente tampouco deve ser confundida com um egoísmo consciente do ponto de vista daquele que age. 
Um dos mais recorrentes destes ataques consiste na crítica de que este modelo seria empiricamente inadequado, já que as idealizações que o pressuposto da racionalidade requer não representariam o comportamento factual dos agentes. ${ }^{3}$ Os críticos reivindicam portanto que, como os seres humanos não se comportam como maximizadores racionais, $i . e$. como as evidências empíricas não correspondem à teoria que toma por base a ação racional dos agentes, então esta concepção deveria ser abandonada. ${ }^{4}$

Dada esta crítica, o propósito do presente artigo é investigar qual papel o postulado da racionalidade ocupa (ou pode legitimamente ocupar) na ciência econômica, à luz da discussão que Karl Popper - talvez o maior o filósofo da ciência do século XX - conduziu sobre essa questão. A escolha da abordagem de Popper como diretriz para esta investigação tem uma razão: os quase 80 anos passados desde a criação dos conceitos popperianos de lógica da situação e princípio da racionalidade. ${ }^{5}$ De fato, em suas primeiras formulações, tais conceitos datam do final da década de 1930. Não obstante, o escrutínio do tema por parte dos economistas e outros cientistas sociais não atraiu muita atenção. Esta é uma situação que causa estranheza, tendo em vista que, em sua autobiografia, Popper (1974) refere explicitamente que a lógica situacional é uma generalização do método usado na economia neoclássica. ${ }^{6}$

O interesse pelo tema decorre do fato de que Popper reconheceu que tanto o princípio da racionalidade quanto o modelo da lógica situacional foram fundamentais para o desenvolvimento da análise que fez da lógica das ciências sociais. Entretanto estes conceitos

3 Outro problema correlato, também clássico na literatura, refere-se à crítica de que o suposto da racionalidade promoveria uma - indesejável - confusão dos aspectos positivos e normativos na teoria econômica padrão. A esse respeito ver, por exemplo, Frank, R.; Gilovich, T.; Regan, D (1993). Não obstante a relevância desta questão, por fugir do escopo dos temas do presente artigo, seu tratamento não é aqui enfrentado.

4 Por diferentes razões, tanto as críticas de Simon (1969) como as de Sen (1974) remetem ao problema aqui explicitado.

5 O segundo já é tratado na próxima seção, ao passo que o exame do primeiro deve aguardar a seção 4 .

6 "Não considerei, entretanto, essa análise importante para a explicação histórica, e o que tive como importante exigiu mais alguns anos para amadurecer. Trata-se do problema da racionalidade (ou "princípio da racionalidade", ou "método zero", ou "lógica da situação"). Entretanto, durante anos, a tese banal - em versão mal interpretada - deu margem, sob o título de "modelo dedutivo", ao aparecimento de larga bibliografia. O aspecto realmente 
custaram a amadurecer, e essa demora teria dado margem a toda uma gama de interpretações equivocadas. Em que pese esse fato, alguns metodólogos atribuíram tanta importância a esta parte da epistemologia de Popper especificamente voltada para as questões das ciências sociais que chegaram inclusive a identificar a incorporação do dualismo metodológico ao longo de sua trajetória intelectual. (Hands, 1985 e 1992; Caldwell, 1991). Sempre tendo em mente o problema da inadequação empírica levantado contra a utilização do postulado da racionalidade na ciência econômica, outra forma de se delinear a questão central que o artigo busca investigar é indagar: qual seria o estatuto epistemológico do princípio da racionalidade nas teorias econômicas que contempla uma solução satisfatória para essa questão?

Três respostas alternativas a esta pergunta são aqui investigadas, tendo suas formas lógicas explicitadas. Na seção 2, investiga-se a possibilidade de considerar o postulado da racionalidade como um enunciado nomológico, vale dizer, como uma lei do comportamento dos agentes. Neste caso, funcionando como uma lei, o postulado da racionalidade deveria localizar-se no plano lógico das teorias econômicas. Esta foi a primeira opção de Popper, nas décadas de 1930/1940, e reflete sua concepção da época, segundo a qual as ciências, fossem elas humanas/sociais ou naturais, deveriam buscar explicações causais nas suas respectivas áreas de investigação. Essa proposta implica necessariamente que a estrutura lógica assumida pela ação racional será um modelo nomológico/hipotético dedutivo.

Na seção 3 investiga-se nova possibilidade, nomeadamente, a de se considerar o postulado da racionalidade como um axioma da teoria, como o fez Mises (1949) em sua obra Ação humana: um tratado de economia. Enquanto axioma, o postulado da racionalidade funcionaria como um a priori lógico e localizar-se-ia naturalmente também

importante do problema, o método da análise situacional, que apresentei em The Poverty em 1938 e depois esclareci mais amplamente no capítulo 14 de The Open Society desenvolveu-se a partir do que eu havia anteriormente chamado "método zero". O importante, no caso, era a tentativa de generalizar o método da teoria econômica (teoria da utilidade marginal), de sorte a torná-lo aplicável às outras ciências sociais teóricas. Nas formulações que posteriormente lhe dei, esse método consiste em construir um modelo da situação social que inclua especialmente a situação institucional em que o agente está atuando, de modo a explicar a racionalidade (o caráter zero) de sua ação. Tais modelos são, nas Ciências Sociais, as hipóteses suscetíveis de comprovação e os modelos que sejam "singulares", mais especificamente, correspondem às hipóteses singulares da História (hipóteses em princípio comprováveis)." (Popper, 1974:125-126. O grifo é nosso). 
no plano lógico das teorias econômicas. Sendo assim, a explicação da ação humana para a Escola Austríaca também é do tipo que busca desvendar os mecanismos causais relevantes.

Já a terceira possibilidade, abordada na seção 4, consiste na opção por considerar o estatuto epistemológico do postulado da racionalidade como regra metodológica ou como máxima regulativa da investigação social. Neste último caso, o postulado da racionalidade não mais deve ser entendido como se fizesse parte do plano lógico das teorias econômicas, mas sim como se funcionasse num plano lógico superior, dito metodológico ou metateórico. Isso implica que se abre mão de considerá-lo como fazendo parte do âmbito "positivo" das teorias (que procuram responder à questão "como é o mundo?"). Ao invés disso, faz-se agora uma tentativa de compreendê-lo como fazendo parte do âmbito "normativo", que é típico das propostas metodológicas. Neste plano metateórico, a questão central passa a ser: "como devem ser elaboradas as teorias que objetivam entender o mundo, no caso, o mundo social?". No caso específico das ciências humanas/sociais, a pergunta naturalmente seria: "como deve ser entendida a ação humana no contexto social?".

Essa opção foi assumida por Popper a partir da década de 1960 e remete à concepção de certo dualismo metodológico, i. e., a existência de um método próprio para as ciências sociais, proposição à qual se fez alusão acima. Assumindo-se esta opção, a estrutura lógica mais adequada para se representar a ação racional será um silogismo, que não mais envolve a necessidade premente de leis para a explicação da ação. Na medida em que a terceira proposta para o estatuto epistemológico do postulado da racionalidade abre mão da relevância do caráter nomológico para a explicação social, consequentemente também a busca por explicações causais para a ação é abandonada. O que está em destaque neste momento é a proposta da adoção de outra forma de se interrogarem os fenômenos na esfera social, norteada agora pela busca de explicações intencionais.

Na quinta seção, argumenta-se que a terceira resposta à indagação inicial consegue contornar satisfatoriamente as críticas de inadequação empírica do modelo de decisão racional nas teorias econômicas. Além disso, propõe-se também que ela se coaduna com algumas propostas afins, desenvolvidas por dois outros eminentes filósofos da ciência do século passado, Thomas Kuhn e Imre Lakatos. 
O artigo conclui-se com uma breve seção em que se faz um resumo dos principais achados e se encaminham algumas reflexões adicionais sobre o tema.

\section{O Princípio da Racionalidade como Lei Geral}

$\mathrm{Na}$ ciência econômica, a concepção de que agentes tomam decisões e que estas, sob determinadas condições de contorno, são racionais, exibe dois aspectos relevantes. $\mathrm{O}$ primeiro diz respeito à forma de se conceber o comportamento do agente frente ao leque de opções que lhe estão ao alcance. $\mathrm{O}$ segundo trata desta ação deslocada para o ambiente do mercado, cujo funcionamento é descrito pela teoria econômica clássica.

A abordagem teórica hoje dominante na ciência econômica considera que a economia deva ser abordada por meio do método nomológico/ hipotético dedutivo. Esta perspectiva avaliza o uso do postulado da racionalidade enquanto uma lei fundamental da ação humana, que congrega características comportamentais psicológicas (crenças e desejos) e hedonísticas (finalidades). Segundo essa lei, os agentes perseguem intencionalmente seus objetivos, preferindo despender menos esforço do que mais esforço a fim de maximizá-los.

As hipóteses básicas acerca do comportamento dos agentes em suas interações, que estruturarão a concepção legaliforme do comportamento racional, podem ser simplificadamente apresentadas conforme segue:

Hl. os agentes dispõem de uma estrutura determinada e ordenada de preferências (que representam seus desejos);

H2. as preferências são completas (o agente prefere $a$ a $b$ ou $b$ a $a$ ou é indiferente entre $a$ e $b$ ) e transitivas (se o agente prefere $a$ a $b$ e $b$ a $c$, então necessariamente preferirá $a$ a $c$ );

H3. as preferências são exógenas (formadas fora do âmbito da modelagem) e permanecem inalteradas durante o processo de trocas;

H4. as preferências de cada agente econômico são independentes, i. e. incomparáveis com aquelas dos demais agentes; 
H5. os agentes atribuem diferentes utilidades aos resultados possíveis de suas ações,

H6. os agentes atribuem probabilidades à obtenção dos resultados esperados, aos quais foram atribuídas utilidades,

H7. os indivíduos agem movidos fundamentalmente pelo autointeresse: agem com o objetivo de satisfazer seus interesses pessoais, desconsiderando outros aspectos tidos como irrelevantes no processo;

H8. sendo as crenças do agente abaladas pela incerteza quanto ao alcance de resultados específicos, sua tomada de decisão vai considerar a média das utilidades que lhe trazem as ações adotadas em resposta às probabilidades de ocorrência dos diferentes estados, sua utilidade esperada, a qual ele se empenha em maximizar.

Pode-se considerar que $\mathrm{Hl}-\mathrm{H} 8^{7}$ nada mais são do que o desdobramento de uma hipótese mais simples, "Existe o homo oeconomicus", ou seja, existe um agente humano que se comporta segundo o postulado da racionalidade. De acordo com a perspectiva que considera este conjunto coeso de hipóteses uma lei, deve-se conceber a estrutura lógica da ação humana a partir do modelo nomológico/hipotético dedutivo. Este modelo requer que as explicações científicas sejam formuladas como um argumento dedutivo composto por duas partes. A primeira consta de um conjunto de sentenças Explanans (em latim, "aquilo que explica"), compostas por Leis Gerais L1, L2, L3, ..., Ln e por outros enunciados, chamados de Condições Iniciais, C1, C2, C3 ..., Ck, os quais fazem asserções sobre fatos ou circunstâncias particulares do fenômeno em questão. A segunda parte consiste de uma conclusão representada pela sentença E, Explanandum,(em latim: "aquilo que se deseja explicar"). Sua estrutura exibe os seguintes contornos (Hempel, 1942):

7 H1-H8 dizem respeito apenas às preferências dos agentes. Como visto, preferências referem-se aos desejos que os agentes buscarão realizar. Entretanto, para que a ação racional possa ocorrer, algumas restrições com relação às crenças dos agentes também precisam ser satisfeitas. Por exemplo, elas precisam ser logicamente coerentes. De fato, o agente não pode acreditar em A e não-A simultaneamente. Caso o fizesse, estaria ferindo o segundo princípio fundamental da lógica clássica (princípio da não contradição), o que indubitavelmente o conduziria à tomada de decisões "irracionais". Supõe-se também que o agente conheça (ou creia conhecer) as prováveis consequências de cada possibilidade de ação. 


$\left.\begin{array}{l}\begin{array}{l}\text { [A] } \mathrm{L} 1, \mathrm{~L} 2, \mathrm{~L} 3, \ldots, \mathrm{Ln} \\ {[\mathrm{B}] \mathrm{C} 1, \mathrm{C} 2, \mathrm{C} 3, \ldots, \mathrm{Ck}} \\ \hline \text { [C] } \quad \mathrm{E}\end{array}\end{array}\right\} \begin{aligned} & \text { Premissas } \\ & \text { (ou sentenças Explanans) } \\ & \text { Conclusão (ou sentença Explanandum) }\end{aligned}$

Para o caso ora em pauta, sejam $[\mathrm{A}]$ e $[\mathrm{B}]$ as premissas do argumento (Explanans), sendo que [A] é uma lei fundamental do comportamento/da ação humana (aquilo que acima foi referido como o postulado da racionalidade e que agora é considerado como uma lei, que terá sua formulação derivada de H1-H8). Como uma lei geral apresenta a forma "Sempre que A, então B" (cf. Hempel, 1966), então a formulação desta lei geral do comportamento humano pode ser simplificadamente expressa, por exemplo, como "Sempre que

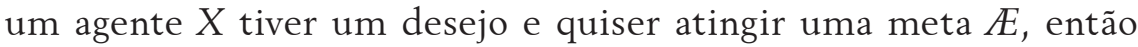
ele se decidirá pela opção, e apenas por essa opção, que seja (ou que pareça ser, à luz de suas crenças) a mais apropriada para maximizar seus resultados esperados." Considere-se, adicionalmente, que [B] é o conjunto das condições iniciais do modelo, $i$. e. toda a pauta axiológica do agente. Finalmente, seja [C] a ação que se deseja explicar/ prever (Explanandum).

Neste caso, a conclusão [C] do argumento, a alegação "O agente $X$ fez $A$ ", será devidamente explicada se e somente se for possível identificar que: $X$ queria $\overparen{E} ; X$ acreditava (sabia, considerava) que a execução de $A$ constituía, para ele, nas circunstâncias dadas, um meio para ocasionar $Æ ; X$ acreditava não existir, nas circunstâncias dadas, outra ação capaz de dar lugar a Æ e que fosse para ele no mínimo tão desejável quanto $A ; X$ não tinha nenhum outro desejo que, nas circunstâncias dadas, suplantasse seu desejo de ocasionar $Æ ; X$ sabia como fazer $A$ e finalmente $X$ estava em condições de fazer $A$. (Churchland, 1970: 221). 
Montando a estrutura nomológico/hipotético dedutiva do argumento, chega-se ao seguinte esquema:

[A] L1: $(X)(E)(A)(\operatorname{Se}(1),(2),(3),(4),(5),(6)$, então $X$ faz $A)$.

[B] (1) $X$ queria $A E$.

(2) $X$ acreditava (sabia, considerava) que a execução de $A$

constituía, para ele, nas circunstâncias dadas, um meio para ocasionar $A$.

(3) $X$ acreditava não existir, nas circunstâncias dadas, outra ação capaz

de dar lugar a $A E$ e que fosse para ele no mínimo tão desejável quanto $A$.

(4) $X$ não tinha nenhum outro desejo que, nas circunstâncias dadas, suplantasse seu desejo de ocasionar $A$.

(5) $X$ sabia como fazer $A$.

(6) $X$ estava em condições de fazer $A$.

Explanans

[C] (7) $X$ faz $A$

Explanandum

Em suas primeiras obras de grande repercussão, Popper $(1938,1945)$ corroborou totalmente esta perspectiva metodológica. Naquele momento, não obstante sua já presente preocupação com o falseacionismo, a forma lógica correta de explicação científica consistia, para ele, no esquema nomológico/hipotético dedutivo, independentemente da área de investigação a que se circunscrevesse o fenômeno. Sendo assim, o estatuto epistemológico do princípio da racionalidade equivaleria ao de lei geral do comportamento humano, mesmo que esta fosse uma lei trivial. Em A Sociedade Aberta e seus Inimigos, Popper (1945: 273) explicitou esse caráter legaliforme que então atribuía ao princípio da racionalidade.

A maior parte das explicações históricas faz um uso tácito nem tanto de leis sociológicas e psicológicas triviais, mas do que chamamos [...] a 'lógica da situação'; quer dizer que, além das condições iniciais que descrevem os interesses, objetivos pessoais e demais fatores da situação [...], essas explicações históricas supõem tacitamente, como primeira aproximação, a lei geral trivial de que as pessoas normais atuam, em geral, de forma mais ou menos racional. 
Vale destacar que, no modelo nomológico-dedutivo de explicação científica, as leis desempenham papel fulcral. São elas que fornecem o elo em razão do qual as circunstâncias particulares expressas em [B] podem servir para explicar a ocorrência de um evento. Alguma lei geral é sempre pressuposta quando se diz que um evento particular foi causado por outro evento. Isto significa afirmar que aquilo que se pressupõe neste tipo de explicação baseado em leis é o chamado princípio da causalidade. Este princípio, por sua vez, é um princípio metodológico, que consiste em uma determinada forma de se interrogarem os fenômenos da natureza (ou os fenômenos sociais), buscando descobrir as causas desconhecidas de efeitos conhecidos.

Mas o que significa dizer que a condição $C$ é a causa do resultado/ efeito $E$ ? Significa que o primeiro está envolvido na ocorrência do segundo, dadas as leis que governam o comportamento das entidades e processos que constituem $C$ e $E$. O cientista procura identificar algumas das condições que produzem o Explanandum, ou que conferem a ele alguma de suas características distintivas. Isso equivale dizer que, segundo essa visão, trata-se de descobrir as condições que existiam antes da ocorrência do evento que, dadas as leis que governam as regularidades de fenômenos deste tipo, eram suficientes para produzir o evento em pauta.

Segundo a perspectiva tradicional em filosofia da ciência, a descoberta da relação causal entre duas ou mais variáveis concernentes a algum fenômeno natural ou social é, no fundo, o objetivo último da investigação científica. Isto porque é precisamente o conhecimento das relações entre a causa e efeito mantidas por dois eventos concatenados no tempo que permite a explicação de seu comportamento nomológico, isto é, legaliforme. Assim, para o cientista, dizer que $C$ é a causa do efeito $E$, para o caso de um evento um pouco mais complexo que possa ser desdobrado em uma série de subeventos $C_{i}$, que ligam $C$ a $E$, significa também poder explicar de que modo a transição de cada $C_{i}$ para $C_{i+1}$ é governada por uma (ou mais) lei(s) $L_{i}$.

Consoante esse tipo de raciocínio, nas ciências sociais, a busca por uma explicação da ação baseada em leis, ou baseada em relações de causa-efeito, supõe que a racionalidade funcione como esse elo legaliforme, representado em [A] por Ll. Todas as condições iniciais (1) a (6) expressas em [B], ou seja, todos os desejos, crenças e pautas axiológicas do agente poderiam ser, segundo essa abordagem, enten- 
didos como constituindo as causas do seu comportamento (efeito). O efeito, por sua vez, nada mais é que o comportamento que se deseja explicar, expresso pelo Explanandum, em [C].

Esta visão replica o sentido em que o princípio da causalidade é tomado na física. Por exemplo: quando se estabelece uma lei geral do tipo: "sempre que metais são submetidos a uma elevação de temperatura, eles se dilatam", o que se está alegando é que a elevação da temperatura (lei geral da física) é o elo em razão do qual determinadas condições iniciais (como, por exemplo, a presença de fogo), podem ocasionar a elevação da temperatura de uma barra de ferro e portanto causar a dilatação do metal (efeito). Note-se entretanto que só foi possível aos cientistas chegar a esta conclusão acerca do comportamento (factual) da natureza porque ela foi "interrogada" com base no princípio da causalidade. E só foi possível estabelecer um enunciado com força de "lei" porque, ao ser interrogada desta forma ("a elevação da temperatura causou a dilatação do metal?"), a natureza respondeu "sim" em virtualmente todos os testes empíricos realizados.

Tanto o esquema nomológico-dedutivo quanto o esquema da lógica situacional são deterministas em igual medida: em ambos os casos, as condições iniciais têm o papel de causas que só desencadeiam os efeitos que atribuímos a eles em decorrência da lei que os abrange, que é um componente lógico central. Assim, nas obras supracitadas, Popper concorda com Hempel que a explicação nas ciências sociais é tão dependente de causalidade nomológica como a explicação nas ciências naturais. $\mathrm{Na}$ análise da situação, a explicação racional (isto é, a explicação que envolve as razões de um agente para a sua ação) é moldada a partir da explicação natural. Estes dois esquemas seriam idênticos quer se tratasse da sua estrutura lógica, quer se tratasse da opção metodológica envolvida. Isto porque, se a asserção universal (a lei teórica "sempre que A, então B") constitui a parte nomológica do esquema de explicação nomológico-dedutivo, parecia a ambos os autores evidente que o princípio da racionalidade desempenhasse este mesmo papel explicativo nas ciências sociais, conforme esquematizado no quadro abaixo: 


\begin{tabular}{|c|c|}
\hline Esquema de Explicação Nomológico-Dedutivo & Esquema de Explicação da Lógica Situational \\
\hline $\begin{array}{l}\text { Explanans: }[\mathrm{A}] \text { Lei geral } \\
\text { [B] Condições Iniciais }\end{array}$ & $\begin{array}{c}\text { Explanans: }[\mathrm{A}] \text { Princípio da racionalidade } \\
\text { [B] Condições Iniciais }\end{array}$ \\
\hline Explanandum: Evento Natural & Explanandum: Evento Social \\
\hline
\end{tabular}

Tanto no caso em que o princípio da racionalidade é tratado como lei geral do comportamento humano (como o faz Popper no final dos anos 1930 e nos anos 1940) como no caso em que ele é tomado como um axioma da teoria (como o faz Mises, que será analisado na próxima seção), se considera que ele se localize no mesmo nível, nomeadamente no plano lógico das teorias. Sendo assim, ele necessariamente está relacionado à proposta de oferecer uma descrição adequada acerca daquilo que "é" o comportamento do agente, dada a precípua função positiva que as construções teóricas carregam consigo, sempre segundo a abordagem tradicional, seja em filosofia da ciência, seja na economia. Como os problemas e as críticas que suscitam ambas as possibilidades de categorização - lei geral do comportamento humano ou axioma - são semelhantes, eles serão apresentados e discutidos ao final da seção seguinte.

\section{O Princípio da Racionalidade como Axioma}

\subsection{Ação Racional e Ação Eficiente}

Uma defesa da tese de que o princípio da racionalidade seria um axioma da teoria econômica foi levada a cabo por Ludwig von Mises (1949). Em uma de suas obras mais conhecidas - Ação Humana: um tratado de economia -, Mises considera o postulado da racionalidade como um axioma, $i$. e . como princípio lógico e portanto válido a priori. Enquanto elemento a priori, a racionalidade diria respeito às condições intelectuais do pensamento, necessárias (não podem não ser), universais (valem para todos os homens em todos os tempos) e anteriores a qualquer momento da experiência, sendo portanto rigorosamente verdadeiro. ${ }^{8}$

8 O sentido atribuído à racionalidade por Mises, de a priori lógico, remete a Kant, à sua confiança na lógica aristotélica e na ideia de que os princípios lógicos representam "as formas do pensamento", ou seja, que não se pode pensar senão de acordo com eles. A definição 
Segundo Mises, viver, para o homem, seria a todo instante o resultado de escolhas, e estas seriam sempre racionais. Para ele, diferentemente do que ocorre com todos os outros animais, que são guiados pelos impulsos de preservação e proliferação, o homem teria o poder de comandar até mesmo estes impulsos. Caso não os controlasse, mesmo esses descontroles poderiam ser explicados como ações racionais, no seguinte sentido: "Quando aplicamos os meios escolhidos para atingir os fins, os termos racional e irracional implicam um julgamento sobre a oportunidade e a adequação do procedimento empregado." (Mises, 1949: 20).

Essa formulação equivale a afirmar que, mesmo ao errar, os indivíduos não agem de forma irracional, no sentido vulgar do termo, mas sim de forma ineficiente. A noção de eficiência, nesse caso, possui uma conotação completamente diferente da acepção de racionalidade. Quando erra, o homem escolhe uma ação inadequada como meio para atingir o fim desejado. Ele é racional, entretanto, no sentido que sua ação é o resultado de uma deliberação sensata. Embora defeituosa, é uma tentativa de atingir um objetivo determinado, a despeito do fato de ter se mostrado uma tentativa ineficaz. A este respeito, Watkins corroborou a perspectiva de Mises, ao afirmar: "Tenho poucas dúvidas de que o que se condena tipicamente como conduta irracional é geralmente um tipo de conduta que, de fato, é mais ou menos racional em relação a uma apreciação equivocada da situação." (Watkins, 1970: 89).

Para Mises, usa-se o princípio da racionalidade quando se deseja compreender a ação de outrem, $i . e$. estabelecer quais eram as suas metas e definir por que se pensou que aqueles meios seriam os melhores disponíveis naquele momento para atingir os objetivos almejados. Sob este prisma, decisão racional significa decisão adequada e não decisão acertada, ou livre de erros de julgamento. Sendo assim, tudo aquilo que a mente humana pudesse explicar seria sempre racional, no sentido que a tentativa de explicação constitui um esforço para estruturar os fenômenos do universo.

de a priori lógico de Mises equivale à definição do a priori analítico kantiano: enunciados cujos predicados já se encontram encapsulados nos sujeitos. Assim, da mesma forma como "triângulos são figuras geométricas com três lados" consiste, para Kant, num juízo analítico a priori, "seres humanos são racionais", constitui esse a priori lógico para Mises. 
Não obstante, Mises pressupõe um limite a partir do qual a teoria não pode avançar. Trata-se daquilo que ele denominou "dado irredutível", ou um "fato irracional". O procedimento de toda ciência social consistiria em um desdobramento intelectual dos fenômenos, até o ponto em que o cientista se deparasse com algum dado irredutível cuja origem não pudesse ser rastreada até outros fenômenos. Entre os fatos irracionais ou dados irredutíveis encontram-se os instintos, os desejos, os julgamentos de valor, os objetivos finais e as causas da ação humana. ${ }^{9}$

Ocorre que, quando o princípio da racionalidade é tratado como um a priori lógico - necessário, universal e anterior à experiência -, como o faz Mises, a principal crítica é que ele acaba por se desfazer em uma tautologia sem poder analítico. Como, no decorrer do processo decisório real, qualquer indício de irracionalidade pode imediatamente ser catalogado como um dado irredutível, a teoria estaria, por assim dizer, "blindada" contra a crítica.

O que dá ensejo a esse problema é o fato de que agentes racionais não se comportam, de fato, como maximizadores racionais. A racionalidade real é uma racionalidade limitada, no sentido de possibilitar falhas e consequentemente decisões equivocadas. Standards ideais de racionalidade, como por exemplo o estatuto de axioma que Mises lhe atribuiu, estão longe de uma caracterização ou de uma descrição da racionalidade real dos agentes. O postulado do comportamento racional maximizador de utilidade é uma idealização que ancora a teorização das ações dos agentes econômicos. Não obstante, não é incomum a crítica de que existe inadequação empírica do modelo, em decorrência do fato de que pessoas reais lançam mão de procedimentos de decisão subótimos nas situações de escolha com as quais se defrontam.

Talvez por essa razão, em diversos momentos Popper alega que o princípio da racionalidade é falso. Manter esta afirmação é reconhecer que alguns agentes "nem sempre agem de uma forma adequada à situação em que se encontram". (Popper, 1967, 361). Para ilustrar seu ponto, Popper descreve um motorista afobado "desesperadamente tentando estacionar seu carro quando não há vaga de estacionamento livre." (Popper 1967, idem).

9 Tal visão difere do que fará Popper, em sua busca de transformar esses "dados irredutíveis" em fatores objetivos, como se terá ocasião de constatar a seguir. 
Torna-se evidente que a situação real ou objetiva é tal que, apesar do fato de que não há vagas de estacionamento, o condutor persiste em tentar estacionar seu carro.

Ou seja, um comportamento patentemente "irracional". De forma explícita, Popper insiste em distanciar sua posição daquela de Mises. Em suas palavras: "[...] o princípio da racionalidade parece-me claramente falso, mesmo em sua formulação mais fraca [...]". (Popper 1967, 360). E ainda: "Há, como já indicado, boas razões para acreditar que o princípio da racionalidade, mesmo em sua formulação mínima, é realmente falso [...] (Popper 1967, 362).

Seria enganoso portanto associar sua posição com o apriorismo de Mises, como Latsis insistiu em fazer em seu artigo de 1976 (Latsis 1976, 6). Popper estava claramente incomodado com esse tipo de associação, alertando o leitor contra qualquer possível confusão acerca deste ponto: "Assim, não se pode dizer que eu o [o princípio da racionalidade] trate como a priori válido". (1967, 362). No mesmo espírito, ele também denunciou aqueles que poderiam ser tentados a descrever este princípio como uma tautologia: "a tautologia é obviamente verdade, no entanto nós fazemos uso do princípio da racionalidade meramente como uma boa aproximação à verdade, reconhecendo que ele não é verdadeiro, mas falso" (1967, 364). Em suma, desde o início, Popper considera que é importante distinguir sua posição de qualquer forma de apriorismo e esse distanciamento justifica-se em decorrência da existência daqueles comportamentos factuais dos agentes que podem ser descritos como "irracionais". Isto porque, caso o princípio da racionalidade fosse, de fato, válido a prio$r i$, os comportamentos reais dos agentes precisariam espelhar isso em cem por cento dos casos observados, o que não ocorre na realidade.

\subsection{O Problema da Inadequação Empírica}

$\mathrm{O}$ que se entende por irracionalidade de um agente seriam alguns comportamentos que não se coadunam com as restrições impostas pelo postulado da racionalidade, seja ele interpretado como lei geral do comportamento humano, seja ele entendido como axioma da teoria. Estudos empíricos realizados por psicólogos cognitivos concluem que a hipótese segundo a qual os agentes humanos comportam-se 
racionalmente é falsa. O que se entende por irracionalidade pode ser explicitado basicamente de duas formas: agentes que chegam a conclusões que não têm como ser justificadas pelo seu conhecimento e/ou agentes que chegam a conclusões ou decisões que não são as melhores que poderiam ter sido, à luz do conhecimento e da evidência para ele disponíveis naquele momento. Alguns exemplos típicos de irracionalidades dos agentes humanos, repetidamente observados nos testes empíricos seriam (Sutherland, 1992; Tversky, Kahneman, 1981):

(i) Acreditar em contradições (ou seja, as crenças não obedeceriam à restrição de serem logicamente coerentes),

(ii) Não acreditar nas consequências daquilo em que se acredita,

(iii) Intransitividade de preferências, inversão de preferências,

(iv) Fazer escolhas baseadas em estimativas equívocadas de probabilidades,

(v) Fraqueza de vontade (i. e. não fazer aquilo que se acredita dever fazer),

(vi) Autoengano (sinceramente não acreditar naquilo que se sabe que se deve acreditar).

A suposição do comportamento racional possui uma importância fulcral na ciência econômica, conforme já assinalado. É um problema importante para a filosofia da economia a adequação empírica da concepção de decisor racional, como definido na seção 2 , ou seja, a suposição consoante a qual cada agente possui um rol de preferências ordenadas, transitivas, etc., e que escolhe o curso de ação mais favorável para a maximização da utilidade. Se o comportamento real do agente não está em conformidade com essas descrições, é necessário que uma resposta adequada seja endereçada.

Uma das reivindicações mais recorrentes, por parte dos críticos ao uso do modelo de racionalidade na ciência econômica, é a de que o egoísmo, enquanto componente essencial da racionalidade do agente, deve ser rejeitado. Tal rejeição não deve ser exercitada porque se crê que os agentes sejam movidos pela adesão a sistemas morais, ou 
porque seja falso que o interesse pessoal desempenhe papel relevante em grande número de decisões, mas sim porque a teoria da escolha racional oferece uma descrição circularmente fundamentada acerca do que representa a motivação do agente. Segundo os críticos, sempre é possível argumentar e fazer parecer que o comportamento do agente foi racional, no sentido de autointeressado e maximizador da utilidade, não importando se o comportamento de fato foi egoísta, altruísta, ou qualquer combinação intermediária de ambos.

Com o intuito de escapar dessa crítica de circularidade, é possível relaxar $\mathbf{H 7}$ e $\mathbf{H 8}$, as hipóteses do comportamento autointeressado do agente e da utilidade esperada de sua ação. Neste caso, o problema da decisão racional passa a ser como especificar a melhor maneira de se decidir, entre um leque de opções de ações existentes e dados os objetivos do agente, qual seria a escolha mais adequada. O conteúdo dos objetivos do agente passa a ser uma questão em aberto. Alguns indivíduos podem vincular utilidade ao autointeresse, outros ao interesse de outrem, outros ainda ao bem comum, etc. No entanto isso não encerra a questão. Permanece válida a crítica da blindagem da teoria contra a refutação, o que é algo indesejável do ponto de vista metodológico, e particularmente indesejável do ponto de vista popperiano. Essa é uma questão delicada, que pode explicar o fato de que Popper, uma vez mais, em outro artigo do final da década de 1960 , tenha alegado que, se considerado como um axioma ou a priori lógico, como queria Mises, o princípio da racionalidade mostra-se claramente falso:

Aqueles que dizem que o princípio da racionalidade é apriorístico querem implicar, naturalmente, que ele é válido a priori, ou verdadeiro a priori. Mas parece-me bastante claro que eles devem estar errados. Isto porque o princípio da racionalidade parece-me claramente falso - mesmo na formulação zero, ou seja, a mais fraca, o que pode ser expresso como: 'Agentes sempre agem de uma forma apropriada à situação em que se encontram' [...] Se um princípio não é universalmente verdadeiro, então ele é falso. Portanto, o princípio da racionalidade é falso. Penso que não há saída para isto. Consequentemente, devemos negar que ele seja válido a priori. (Popper, 1969:171-172) 
Quando Popper insiste em afirmar que o princípio da racionalidade é falso, sua intenção é esclarecer que ele não corresponde à realidade, ou seja, os homens não agem desta forma cem por cento do tempo. Com efeito, os estudos empíricos sobre o comportamento dos agentes apontam nessa direção, como visto acima. Ocorre que é exatamente isto que deveria acontecer (evidências empíricas apontando que os agentes agem racionalmente em virtualmente cem por cento dos casos observados), caso o postulado da racionalidade possuísse de fato o estatuto de axioma ou a priori e as condições de necessidade e universalidade que Mises lhe atribuiu. Não obstante, no modelo construído por Mises, todas as vezes que o princípio falha, i. e., a cada contraexemplo encontrado quando se faz o contraste da teoria com a realidade, a cada ação aparentemente "irracional" verificada, já existe um mecanismo autoprotetor na teoria voltado a explicar o que aconteceu. Se algum teste empírico malogrou, se a ação do indivíduo apresentou algum indício de irracionalidade, do tipo (i)-(vi) acima, por exemplo, então se tratava de um dado irredutível.

De forma análoga ao que foi argumentado com relação à possibilidade de o postulado da racionalidade desempenhar o papel epistemológico de axioma, tornou-se também muito difícil sustentar que a racionalidade revelasse uma lei causal que governa o comportamento dos agentes. Caso esta lei existisse, ao se formular a pergunta: "a racionalidade é o elo nomológico em razão do qual a causa do comportamento do agente pode ser elucidada?", a resposta precisaria ser "sim" em virtualmente todos os testes empíricos realizados, à maneira do que ocorreu com a pergunta da física, que utilizamos como parâmetro na seção 2 , acima. Novamente: quando se estabelece uma lei geral do tipo: "sempre que metais são submetidos a uma elevação de temperatura, eles se dilatam", significa que os cientistas já acreditam que tal relação reflita um elo de causa-efeito que exista de fato na natureza. Tal segurança acerca do estatuto nomológico desta alegação universal baseou-se nos testes empíricos, que responderam favoravelmente em virtualmente cem por cento dos casos. Ou seja, a cada vez que, em um laboratório, se elevou a temperatura de uma barra de metal por tempo suficiente, ela se dilatou.

Já o postulado da racionalidade não obteve o mesmo êxito empírico nos testes, conforme já assinalado. Porém, como algum pressuposto de racionalidade parece ser imprescindível, o que terminou por acontecer, para Popper, é que se tornou indefensável pretender que 
existe algo análogo à explicação física para a explicação econômica. É evidente que o mesmo vale para todas as demais disciplinas intencionais, i. e. as chamadas ciências sociais e humanas. Chega-se assim à terceira proposta de definição da função epistêmica exercida pelo postulado da racionalidade nas teorias sociais.

\section{O Princípio da Racionalidade como Regra Metodológica ou Máxima Regulativa da Investigação Social}

Dadas essas dificuldades, na década de 1960 Popper começou a elaborar com maior detalhamento seus conceitos de sociologia da compreensão objetiva, método da compreensão objetiva e lógica situacional, sinalizando uma mudança em relação a sua postura anterior, de defesa veemente do isomorfismo lógico entre as ciências naturais e sociais. Em uma de suas obras dedicadas especificamente à metodologia das ciências sociais, a Lógica das Ciências Sociais, Popper aponta para um método característico - e objetivo - para o âmbito das ciências da sociedade:

Vigésima-quinta tese:

A investigação lógica da Economia culmina com um resultado que pode ser aplicado a todas as ciências sociais. Este resultado mostra que existe um método puramente objetivo nas ciências sociais, que bem pode ser chamado de método de compreensão objetiva, ou de lógica situacional [...] Este método consiste em analisar suficientemente a situação social dos homens ativos para explicar a ação com a ajuda da situação, sem outra ajuda maior da psicologia. A compreensão objetiva consiste em considerar que a ação foi objetivamente apropriada à situação. Em outras palavras, a situação é analisada o bastante para que os elementos que parecem, inicialmente, ser psicológicos (como desejos, motivos, lembranças e associações), sejam transformados em elementos da situação. O homem com determinados desejos, portanto, torna-se um homem cuja situação pode ser

Estud. Econ., São Paulo, vol.44, n.4, p. 847-880, out.-dez. 2014 
caracterizada pelo fato de que persegue certos alvos objetivos; e um homem com determinadas lembranças ou associações torna-se um homem cuja situação pode ser caracterizada pelo fato de que é equipado, objetivamente, com outras teorias ou com certas informações[...] Eu chamo isso, usualmente, de "lógica situacional" ou "lógica da situação". (Popper: 1961:31. Grifo nosso).

Uma das consequências do amadurecimento do conceito de "lógica situacional" foi uma mudança no papel considerado adequado para o princípio da racionalidade nas teorias. $\mathrm{O}$ fato de os indivíduos agirem racionalmente significa que a ação está de acordo com a situação que se lhes apresenta, levando-se em consideração as informações de que dispõem no momento, suas crenças, e toda sorte de outros fatores que ajudam a compor a situação, bem como seus objetivos pessoais. Neste momento, i. e., a partir da década de 1960, o princípio da racionalidade deixa de ser considerado por Popper como um enunciado nomológico, como foi em 1944, e passa a ser entendido como a "máxima regulativa da investigação social" (Farr, 1983).

Em 1966, quando também se debruça sobre os mesmos temas, Popper volta a analisar o estatuto epistemológico desse princípio, investigando sua não refutabilidade. Ele discute então duas alternativas: se o correto seria considerá-lo como hipótese empírica ou como princípio metodológico. No primeiro caso, se uma teoria fosse submetida a um teste e malograsse, não haveria motivos para que se excluísse a possibilidade de que o próprio princípio fosse considerado responsável pelo fracasso, uma vez que uma hipótese empírica participa do corpo do modelo, devendo, portanto, ser submetida a teste junto com todo o resto da teoria. Ocorre que não é isso que se verifica na prática científica real. Via de regra, se uma teoria não passa nos testes, o que se costuma fazer, ou o que a "boa prática metodológica" sugere que se faça, não é rejeitar o princípio da racionalidade. Pelo contrário: no caso de dificuldades empíricas, o que costuma ocorrer é a manutenção do princípio e a revisão da teoria, no caso, o modelo situacional. 
Assim, Popper chegou à conclusão de que o princípio é irrefutável porque não se localiza no plano lógico (teórico), já que ele não pode ser nem axioma, nem lei, nem hipótese empírica da teoria. A irrefutabilidade do princípio da racionalidade decorreria do fato de que ele se localiza em um plano lógico "superior" ao plano teórico, o plano metodológico (ou metateórico). Isto explica o porquê de ele ser utilizado de um modo que exclui a possibilidade de sua própria refutação. Ou seja, talvez ele seja preservado quando os testes empíricos malogram para salvaguardar a refutabilidade de todo o sistema teórico. Essa é justamente a posição que defende Watkins (1970: 87), por exemplo, que considera os princípios como premissas imprescindíveis e irrefutáveis, cuja função principal é justamente garantir a refutabilidade da teoria como um todo:

Em qualquer ciência se requer um corpo considerável de premissas para que se possam derivar logicamente predições refutáveis. Geralmente não será muito difícil substituir uma premissa existente sem diminuir a refutabilidade empirica do sistema. Entretanto, também pode haver premissas das quais pareça praticamente impossivel prescindir sem que se diminua seriamente a refutabilidade do sistema ou sem que ele se converta, inclusive, em um sistema incontrastável. A tais premissas se pode chamar princípios, quer dizer, componentes privilegiados que se considera como irrefutáveis em interesse da refutabilidade de todo o sistema [...] Se o princípio da racionalidade é necessário para deduzir predições sobre as ações a partir de descrições situacionais, parece claro que está dentro dessa categoria.

Sob o ponto de vista estritamente lógico, pode-se caracterizar a compreensão objetiva ${ }^{10}$ como obedecendo outra estrutura silogística, esquematizada conforme segue:

${ }^{10}$ Trata-se aqui de uma clara alusão (crítica) de Popper à "compreensão subjetiva” proporcionada pela Verstehen. Acerca dos problemas acarretados pela falta de critérios intersubjetivos de validação no método hermenêutico, ver, por exemplo, Abel (1948). 

[A] Premissa
[B] Premissa

[C] Conclusão

Como se observa, trata-se neste caso de um modelo de explicação lógica bem mais simples que o modelo nomológico/hipotético-dedutivo, tendo em vista que não mais se considera necessária a existência de leis para a explicação. Isso implica também, conforme anteriormente assinalado, que se está abrindo mão do princípio da causalidade como norteador da explicação do fenômeno social.

Aplicando o modelo silogístico para o caso da ação racional, fazem-se as seguintes suposições: seja [C] a conclusão do argumento, i. e. uma descrição da ação que se deseja explicar. Sejam [A] e [B] suas premissas. Seja [A] uma descrição dos objetivos ou das metas do agente e [B] uma descrição das informações, crenças, teorias, bem como das pautas axiológicas às quais a ação obedece. $\mathrm{O}$ que se intenta aqui é explicitar a estrutura lógica da operação mental chamada por Popper de compreensão objetiva. Nesse caso, um esquema lógico tão simples como um silogismo carece ainda de algo. Como o próprio Popper apontou, o que rege o modelo é justamente o princípio de racionalidade, entendido neste momento como o princípio metodológico segundo o qual os agentes sempre agem de maneira adequada à situação em que se encontram. Neste contexto, entende-se também, naturalmente, que os fins e as atitudes de tais agentes são os elementos que dão contorno a essa situação. Chega-se ao seguinte esquema geral:11

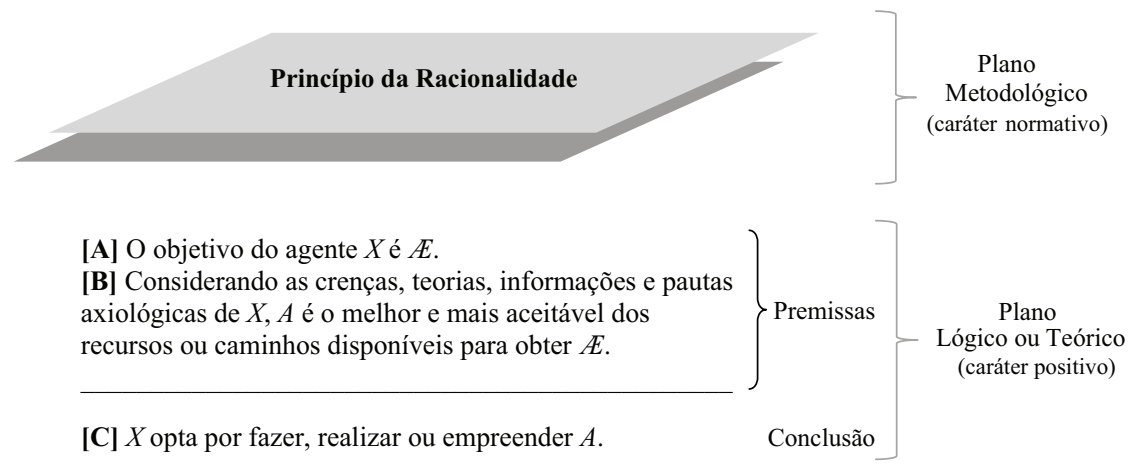

11 Ver Caponi (2012). 
De acordo com esse segundo tipo de estrutura lógica, silogística, é possível entender o princípio de racionalidade como regra metodológica e, portanto, como uma diretriz normativa. Sendo a conclusão [C] a descrição da ação $A$ empreendida por um agente $X$, deve-se formular e contrastar um conjunto premissas que contenha: [A] a atribuição de um desejo ou uma meta $Æ$ ao agente $X$, e [B] a enumeração de um conjunto de informações, crenças, teorias, preferências e pautas axiológicas imputáveis a $X$, sob cuja consideração a ação $A$ poderia ser pensada como a melhor alternativa disponível para alcançar o propósito Æ.

É importante salientar que, no contexto daquilo que Popper propôs com seu método da compreensão objetiva, o principio da causalidade e o princípio da racionalidade constituem distintas maneiras de se interrogarem os fenômenos. O princípio de causalidade estabelece as regras para se explicar causalmente, ou seja, nomologicamente, os fenômenos naturais, ao passo que o principio da racionalidade estabelece as regras para que se possam compreender objetivamente os fenômenos socioeconômicos. Ambos desempenhariam função semelhante, nos seus respectivos domínios - ciências naturais e sociais, respectivamente -, a de servir como diretriz metodológica que indica como deve ser interrogado o fenômeno. A diferença entre ambos consiste no fato de que, enquanto o princípio da causalidade objetiva descortinar as leis, ou as relações de causa-efeito que regem os fenômenos naturais, o princípio da racionalidade prescinde da existência de leis e busca compreender as relações meios-fins que regem as tomadas de decisão dos agentes no âmbito social.

Do ponto de vista adotado por Popper a partir dos anos 1960, não se poderia mais afirmar que a racionalidade é o elo nomológico que explica como as condições iniciais causam a ação (que se deseja explicar), no mesmo sentido que a elevação da temperatura é o elo nomológico que explica como o fogo (e outras condições iniciais dadas) são a causa da dilatação de uma barra de metal. A formulação correta, desta nova perspectiva, é afirmar que a racionalidade é o meio adequado para a ação voltada a alcançar certo fim.

Sendo assim, compreender objetivamente uma ação não significa determinar as causas de um comportamento, ou mesmo os motivos que o desencadearam. Os objetivos, as informações e as pautas axiológicas, sob cuja consideração uma ação pode ser julgada como adequada 
a uma situação, não são a causa eficiente dessa ação. Isto porque a compressão não exibe uma conexão causal, mas sim uma conexão teleológica, i. e. uma conexão que faz sentido da ação. Porém só foi possível chegar a esse entendimento porque o princípio da racionalidade, nesse momento, faz o papel de regra metodológica ou de guia para a investigação científica. Enquanto tal, ele deve conduzir o olhar do cientista social à investigação do fenômeno em pauta, ou seja, no processo de ampliação, aprofundamento e estabelecimento dos pormenores da teoria na qual se insere. Como não poderia ser diferente, parte importante desse processo é o contraste com os dados empíricos.

Entendido desta terceira maneira, o princípio da racionalidade consegue responder bem à crítica de inadequação empírica a que são submetidas as teorias que dele fazem uso. De fato, caso o princípio esteja localizado no plano metodológico, essa crítica específica perde muito de sua força. Isto porque, como se viu, ela era pertinente quando se supunha que o postulado da racionalidade participasse do plano positivo das próprias teorias, ou seja, quando se acreditava que ele pretendesse revelar um aspecto sobre "aquilo que é" o comportamento do ser humano. Não sendo este mais o caso, o que se espera do princípio da racionalidade, neste contexto metodológico, é tão somente servir de guia para os pesquisadores que dele se utilizam conseguirem formular perguntas interessantes à realidade socioeconômica, com o fim de compreender as ações humanas de forma objetiva. Essa forma de se entender o papel epistêmico da racionalidade guarda algumas semelhanças interessantes com o que foi proposto por outros filósofos contemporâneos de Popper.

\section{Popper, Kuhn e Lakatos: Um Ponto de Consenso}

Um dos aspectos mais controvertidos e também mais inovadores da abordagem de Kuhn (1970) sobre o funcionamento da ciência é aquele que a caracteriza, durante os longos períodos de normalidade, em função da existência de um paradigma compartilhado. A própria definição circular envolvendo os conceitos de ciência normal e paradigma, que abre a obra, já deixa claro tanto a imbricação mútua entre ambos os conceitos quanto a importância que Kuhn viria a atribuir ao papel dos paradigmas. 
De fato, uma dentre as várias críticas que Kuhn recebeu após a publicação do livro dizia respeito precisamente a sua falta de precisão semântica com relação a um conceito tão central em sua proposta, como o é o de "paradigma". Uma referência obrigatória nessa linha de críticas é o artigo de Masterman (1970), que identificou 21 sentidos diferentes para o termo, ao longo do livro. No pós-escrito à segunda edição de A Estrutura, de 1970, bem como em seu artigo de 1974, Second thoughts on paradigms, Kuhn reconheceu ter formulado o conceito de paradigma de modo ambíguo, acatando a crítica de que a circularidade envolvendo as definições de paradigma e de ciência normal poderia produzir consequências viciosas. Com o intuito de superar tais dificuldades, nestes textos ele opta por abandonar o antigo e controverso termo, renomeando-o para "matriz disciplinar", e distinguindo três sentidos preponderantes nele encapsulados: modelo heurístico, generalizações simbólicas e os exemplares.

Com relação ao primeiro sentido, de modelo heurístico - que é o mais relevante no contexto da discussão ora em pauta -, um paradigma ou matriz disciplinar fornece ao cientista que dele participa uma particular "maneira de ver o mundo", i. e., fornece um modelo de interpretação que desempenha um claro papel normativo. Não obstante, o mesmo modelo heurístico também estaria comprometido com determinadas concepções metafísicas acerca daquilo que existe no mundo. Nessa mesma linha de argumentação, também é bastante conhecida a metáfora utilizada por Kuhn identificando a investigação científica nos períodos de ciência normal com a resolução de "quebra-cabeças". Os problemas científicos, para ele, consistiam em puzzles, i. e., em enigmas com determinado número de peças, que o cientista precisaria montar até encontrar a solução final. É importante salientar que, para Kuhn, a solução final, tal como a imagem que ilustra a caixa do jogo, já era conhecida de antemão, servindo de guia para a resolução do quebra-cabeças. O paradigma no qual todo cientista se insere, incorporado durante o processo de sua formação profissional, ensina-lhe como deve ser visto o mundo. Por esse motivo a metáfora com o quebra-cabeça é tão interessante. O paradigma é a imagem de mundo que o cientista deve buscar nos testes empíricos, de modo análogo à imagem da caixa do jogo que o jogador deve reconstruir ao longo do processo de montagem. Ou seja, o paradigma, ou a teoria à qual se integra o pesquisador desempenha um papel normativo crucial no fazer científico cotidiano. A formação teórica ensina-lhe não apenas as "regras do jogo", ou seja, as diretrizes 
metodológicas que devem ser obedecidas, mas também quais peças devem ser utilizadas em cada momento, o caminho a ser percorrido e o objetivo a ser atingido.

A consequência mais dramática do ensino deste tipo de diretriz heurística ou metodológica, para Kuhn, é que, sem uma concepção normativa acerca daquilo que "deva ser" o mundo, não haveria investigação possível da realidade. Esse papel normativo, para ele, já seria exercido no plano da própria teoria, entendida no sentido mais amplo de paradigma, conforme apontado acima. Já para Popper, como visto, o papel normativo localizar-se-ia no plano metodológico. Não obstante, para ambos os autores, ele seria absolutamente imprescindível.

A perspectiva apresentada na seção 4 também é plenamente compatível com algumas tentativas de aplicação da metodologia de Lakatos (1970, 1973) - herdeiro, como se sabe, de vários insights da metodologia popperiana - para a teoria econômica neoclássica.

Na proposição de seus programas de pesquisa científicos, Lakatos introduziu dois novos conceitos na filosofia da ciência: o de núcleo rígido (ou núcleo irredutível) e o de cinturão protetor das teorias. Sendo o primeiro o cerne inabalável das teorias, ele é irrefutável porque traria consigo determinadas concepções metafísicas, equivalentes às "visões de mundo" dos paradigmas kuhnianos. Esta é outra forma de afirmar que o núcleo rígido de uma teoria é mantido não falseável por uma decisão metodológica de seus protagonistas. Esse núcleo assume a forma de hipóteses teóricas muito gerais, que constituem a base a partir da qual um programa de pesquisa científica se formará. Alguns exemplos de núcleos rígidos foram, na astronomia copernicana, a suposição de que a Terra e os outros planetas orbitam um Sol estacionário e que a Terra gira em torno de seu eixo uma vez ao dia. $\mathrm{Na}$ teoria de Newton, o núcleo rígido diz respeito à lei da gravidade e às leis de movimento dos corpos. Já na teoria marxista, o núcleo rígido encapsularia a suposição de que a mudança histórica deva ser explicada em termos de lutas de classes, e que os detalhes dessas lutas estariam explicados pela base econômica. Todos os núcleos rígidos, por sua vez, estão envoltos por cinturões protetores, constituídos por toda uma gama de hipóteses auxiliares. 
É justamente essa parte das teorias que será confrontada com a realidade nos testes empíricos, e também ela é que sofrerá modificações na tentativa de salvar a teoria das refutações.

Já as heurísticas, para Lakatos, constituem um conjunto de regras ou técnicas para a resolução de problemas científicos que podem possuir caráter muito geral e filosófico, ou podem ser regras metodológicas. Lakatos distingue dois tipos de regras: a heurística positiva e a negativa. A heurística positiva consiste em um conjunto articulado de indicações acerca daquilo que os cientistas devem fazer. Trata-se da proposição de diretrizes sobre como mudar, desenvolver e sofisticar o cinturão protetor, de maneira a propiciar a previsão de eventos ainda não abarcados pela teoria. Nesse sentido, a heurística positiva é algo mais vago e difícil de caracterizar especificamente em comparação à heurística negativa. Esta última especifica ao cientista quais tipos de pistas de investigação devem ser evitadas. Um exemplo de heurística negativa é a proibição de que, durante o desenvolvimento do programa, o núcleo rígido seja modificado. Qualquer cientista que resolvesse fazê-lo estaria optando, na prática, pelo abandono daquele programa de pesquisa específico.

Weintraub, (1985) e Weiss (2002) procuraram utilizar os principais conceitos da metodologia dos programas de pesquisa científicos lakatosianos para identificar a estrutura da teoria do equilíbrio geral de Walras. Uma de suas propostas era identificar as hipóteses componentes de seu núcleo irredutível, de seu cinturão protetor, bem como de suas heurísticas. Segundo Weiss (2002: 11-12), as hipóteses componentes do núcleo irredutível e as heurísticas - positiva e negativa - do PPC neowalrasiano seriam, em tradução livre, as seguintes:

As suposições do núcleo rígido são:

HCl. Existem agentes econômicos;

HC2. Os agentes possuem preferências com relação a ocorrências;

HC3. De modo autônomo, os agentes otimizam, sujeitos a resultados;

HC4. As escolhas são feitas em mercados inter-relacionados;

HC5. Os agentes possuem todo o conhecimento relevante;

Estud. Econ., São Paulo, vol.44, n.4, p. 847-880, out.-dez. 2014 
HC6. Os resultados econômicos são coordenados, de sorte que devem ser discutidos com referência a teorias do equilíbrio.

$\mathrm{E}$ as heurísticas positivas e negativas são:

PH1. Prossiga e construa teorias em que os agentes econômicos otimizam;

PH2. Construa teorias que fazem predições sobre mudanças nos estados de equilíbrio;

NHl. Não construa teorias em que o comportamento irracional desempenhe qualquer papel;

NH2. Não construa em que o equilíbrio não possua qualquer significado;

NH3. Não teste as proposições do núcleo rígido.

Note-se que HCl-HC3 muito se assemelham a uma simplificação das proposições H1-H8 feitas na seção 2. Não obstante, a partir da perspectiva de Lakatos, as hipóteses aqui são consideradas irrefutáveis, possuindo inclusive certo caráter metafísico, já que compõem o núcleo irredutível do programa de pesquisa. Elas jamais serão testadas, $i$. $e$. colocadas em xeque pelos pesquisadores participantes do programa. A garantia para isso está dada pelo papel desempenhado pelas heurísticas positiva e negativa na proposta de Lakatos. Observe-se também que PHl e NH1, simétricas e complementares, exercem exatamente o papel epistêmico apresentado na seção 4 , segundo o qual o princípio da racionalidade funciona (ou deve funcionar) como regra metodológica. Ou seja, sua função epistemológica consiste em estabelecer as diretrizes em consonância com as quais os participantes dos programas de investigação deverão (ou não deverão) nortear suas pesquisas. Caso optem por contestar estas regras, estarão, na realidade, optando pelo abandono deste programa de pesquisa, proposição esta expressa pela heurística negativa NH3.

Dando um passo além na argumentação, pode-se afirmar que o que deve ser levado em consideração quando se enfrenta o problema da (in)adequação empírica das caracterizações idealizantes dos agentes racionais é que nenhuma interpretação dos fatos obtidos experimen- 
talmente pode ser realizada sem a utilização prévia das próprias propostas da teoria da decisão (ou do princípio da racionalidade, entendido neste momento como regra metodológica).

Uma explicação para a aderência dos participantes dos programas de pesquisa que fazem uso do modelo da racionalidade a essa regra é que o modelo de decisão racional, na acepção de que a ação foi $a d e$ quada à situação, dados as crenças, desejos e objetivos do agente, é tão simples que as descobertas empíricas têm que adaptar-se a ele. Seria impossível, por exemplo, imaginar uma situação inversa, na qual se procuraria elaborar uma teoria da (ir)racionalidade a partir dos dados coletados pelas experiências sobre a (ir)racionalidade dos agentes. Em outras palavras, o que parece estar em causa aqui é a inevitabilidade do apelo metodológico ao postulado da racionalidade. É por esse motivo que Davidson (1984:274) traça um paralelo entre a teoria da decisão racional e a teoria da correspondência da verdade de Tarsky: "A teoria é, em cada caso, tão poderosa e simples e de tal modo constitutiva de conceitos assumidos por posteriores teorizações[...] que devemos tentar adaptar nossos resultados ou nossas interpretações de modo a preservar a teoria."

Caso assim seja, o estatuto epistêmico (ou o legítimo papel) que o princípio da racionalidade tem a desempenhar nas teorias econômicas é o de servir de regra metodológica. E isso foi defendido por Popper em seus artigos mais maduros, da década de 1960, pode ser defendido a partir da perspectiva lakatosiana, tendo em vista o papel que as heurísticas positiva e negativa desempenham em seus PPCs, e poderia ser defendido a partir daquilo que foi proposto por Kuhn. Basta que se atente para a precípua função do modelo heurístico dos paradigmas ou matrizes disciplinares.

Decerto não se estará aqui tentando negar que existiram algumas divergências profundas entre as perspectivas propostas pelos três grandes nomes de epistemologia do século XX. Ao contrário, reconhecidas as profundas divergências, o que se pretendeu brevemente assinalar nesta seção é que, em pelo menos uma questão central, houve coincidência de posições. 


\section{Conclusão}

No estudo da ciência econômica, desistir da tentativa de explicação da ação humana está tão fora de questão como desistir de se procurarem as causas dos fenômenos na física. Dada a relevância do tema, neste artigo foram feitas três tentativas de se entender a função do postulado da racionalidade nas teorias econômicas. Nas duas primeiras, Popper e Mises procuraram localizá-lo no interior das teorias, seja funcionando como uma lei do comportamento humano, seja como um axioma ou a priori lógico. Estas classificações epistemológicas se depararam com problemas. Em especial destacouse a crítica de inadequação empírica do modelo de racionalidade.

Estudos empíricos acerca do comportamento de agentes humanos mostraram que, diferentemente do que é assumido por teorias econômicas e filosóficas, longe de serem perfeitamente racionais, as pessoas não são sequer consistentemente coerentes em suas crenças e preferências. Essas inconsistências refletem-se naturalmente também nas suas ações. Ocorre que estes contraexemplos tampouco podem servir para provar que as pessoas são irracionais na grande maioria dos casos, ou tendencialmente irracionais. Isso começa a ficar claro quando se assume a terceira proposta de Popper e passa-se a entender o postulado da racionalidade como uma regra metodológica para a investigação social.

O que se procurou explicitar na parte final deste artigo foi o argumento segundo o qual sem o contexto metateórico representado pelo suposto da racionalidade, sem os constrangimentos que a teoria da escolha racional explicita (coerência, transitividade, etc.) acerca de crenças e preferências, não se poderia sequer dizer o que é racionalidade. Assim, um bom argumento contra as críticas da inadequação empírica do modelo da racionalidade aplicado às teorias econômicas é a alegação de que não faz sentido pensar que contraexemplos provem que os agentes ajam grande parte do tempo de forma irracional. Chamar alguém ou algum comportamento de irracional já pressupõe um conhecimento prévio sobre o que seja (ou sobre o que deva ser chamado de) racional ou, dito de outro modo: sem o conceito de racionalidade nenhuma entidade pode ser concebida como irracional. Esse conhecimento prévio consiste em um modelo teórico de racionalidade. E o melhor - no sentido de mais simples e abrangente - modelo de que se dispóe até o momento é o da escolha racional. 
Este propõe que o agente racional possui uma pauta coerente de preferências, que obedecem a certos requisitos, e que a escolha racional consiste na seleção da alternativa de ação que acarretará, de acordo com o entendimento do agente naquela circunstância, os resultados mais vantajosos.

Não há como negar que o postulado de racionalidade seja uma idealização da realidade. Enquanto tal, naturalmente ele não reflete o comportamento do agente humano "tal qual ele realmente é". Conforme se argumentou neste artigo, nem poderia fazê-lo, pois tudo indica que ele não deva localizar-se no plano lógico das teorias. Sendo assim, estaria excluída a possibilidade de que ele participasse da esfera positiva, que objetiva dizer como "é" o fenômeno em pauta, no caso o comportamento humano. No entanto, funcionando no plano lógico localizado "acima" do plano teórico - ou seja, no plano metodológico -, o postulado da racionalidade exerce uma função precípua nas teorias. Isto porque, sem os constrangimentos idealizantes acerca do que constitui a racionalidade, não se disporia dos instrumentos que permitem buscar os dados empíricos, a fim de testar a teoria.

Talvez a última resposta elaborada por Popper para elucidar o papel do postulado da racionalidade nas teorias sociais, $i$. e. tratando-o como um princípio metodológico, ajude a explicar as razões epistêmicas pelas quais ele tenha sobrevivido na ciência econômica até agora, em que pesem todos os problemas nele identificados. Ao fim e ao cabo, sem a diretriz metodológica que direciona o olhar do cientista para a realidade em busca da compreensão objetiva da ação humana no âmbito econômico/social, sequer seria possível formular as críticas ao modelo.

\section{Referências}

ABEL, T. The operation called Verstehen. American Journal of Sociology v. 54, n. 3, 1948, pp. 211-218. APEL, K. Comments on Farr's paper (II): some critical remarks on Karl Popper's contribution to hermeneutics, Philosophy of the Social Sciences, v. 13 n. 2, 1983, pp. 183-193

BOWLES, S. Microeconomics; behavior, institutions, and evolution. Princeton: Princeton University, 2004. CALDWELL, B. Clarifying Popper. Journal of Economic Literature, v. 29, n.1, 1991, pp. 1-33.

Estud. Econ., São Paulo, vol.44, n.4, p. 847-880, out.-dez. 2014 
CAPONI, G. Aproximação popperiana à distinção explicação-compreensão. In: OLIVEIRA P. E. (Org.) Ensaios sobre o pensamento de Karl Popper. Curitiba: PUCPR, 2012, pp.187-197.

CHURCHLAND, P. The logical character of action-explanations. The Philosophical Review n. 79, pp. 214-236, 1970.

DAVIDSON, D. On the very idea of a conceptual scheme. In: DAVIDSON, D. Essays on truth and interpretation. Oxford: Oxford University, 1984

FARR, J. Popper's Hermeneutics. Philosophy of the Social Sciences, n. 13, 1983, pp.157-176.

FRANK, R.; GILOVICH, T.; REGAN, D. Does studying economics inhibit cooperation? Journal of Economic Perspectives, v. 7, n. 2, 1993, pp. 159-171.

FRIEDMAN, M. The methodology of positive economics. In FRIEDMAN, M. essays in positive economics. Chicago: University of Chicago, 1966 [1953], pp. 3-46.

HANDS, D. W. Karl Popper and economic methodology: a new look, Economics and Philosophy, v. 1, 1985, pp. 83-99.

.Falsification, situational analysis and scientific research programs: the Popperian tradition in economic methodology. In De MARCHI, N. (Ed.). Post-Popperian methodology of economics: recovering practice. Boston/ Dordrecht/London: Kluwer Academic, 1992.

HEMPEL, C. G. The function of general laws in history. Journal of Philosophy, v. 39, n. 2, 1942, pp. $35-48$.

Filosofia da ciência natural. Rio de Janeiro: Zahar, 1981 [1966].

KUHN, T. A estrutura das revoluções científicas. São Paulo: Perspectiva, 1997 [1970].

. Second thoughts on paradigms. In: SUPPE, F. (Ed.) The structure of scientific theories. Urbana: University of Illinois, 1974, pp. 459-482.

LAKATOS, I. Falsificação e metodologia dos programas de investigação científica. Lisboa: Edições 70, 1978 [1970].

. História da ciência e suas reconstruções racionais. Lisboa: Edições 70, 1978 [1973].

LATSIS, S. A research program in economics. In: LATSIS, S. (Ed.) Method and appraisal in economics. New York: Cambridge University, 1976.

MASTERMAN, M. The nature of a paradigm. In: LAKATOS, I.; MUSGRAVE, A. Criticism and the growth of knowledge. Cambridge: Cambridge University, 1970. pp. 59-89.

MISES, L. von. Ação humana: um tratado de economia. Rio de Janeiro: Instituto Liberal, 1990 [1949].

NADEAU, R Confuting Popper on the rationality principle. Philosophy of the Social Sciences, v .23, n. 4, 1993, pp.446-467

NOZICK, R. The nature of rationality. Princeton: Princeton University, 1993.

PIMENTEL, E. Dilema do prisioneiro: da teoria dos jogos à ética. Belo Horizonte: Argumentum, 2007.

POPPER, K. The poverty of historicism. London and New York: Routledge, 1997[1938]. . A sociedade aberta e seus inimigos. São Paulo: Universidade de São Paulo, 1987 [1945].

. Lógica das ciências sociais. Brasília: Universidade de Brasília, 1978 [1961].

The Rationality Principle, in MILLER, D. (Ed.) Popper Selections. Princeton: Princeton University Press, 1985 [1967], pp. 357-65. First published as La Rationalité et le Statut du Principe de Rationalité. In CLASSEN; EMIL M. (ed.) Les Fondements Philosophiques des Systemes Economiques. Paris: Payot, 1966.

Models, instruments and truth - the status of the rationality principle in social sciences. In POPPER, K. The Myth of the Framework - In defence of science and rationality. London and New York: Routledge, 1994 [1967].

. A pluralistic approach to the philosophy of History. In POPPER, K. The myth of the framework in defence of science and rationality. London and New York: Routledge, 1994 [1969]. 
Autobiografia intelectual. São Paulo: Cultrix, 1977 [1974].

SEN, A. Rational Fools: a critique of the behavioural foundations of economic theory, Philosophy and Public Affairs, v. 6, n. 4, 1974, pp. 317-344.

SIMON, H. The sciences of the artificial. Cambridge: MIT, 1969.

SUTHERLAND, S. Irrationality. New Jersey: Rutgers University, 1992.

TVERSKY, A.; KAHNEMAN, D. The framing of decisions and the psychology of choice, Science, v. 211, 1981, 453-458.

WATKINS, J. Racionalidad imperfecta . In BERGER, R.; CIEFFI, F. (ed.) La explicación en las ciencias de la conducta. Madrid: Alianza, 1970.

WEISS, M. The best way to do economics: moves and countermoves in the history of economic methodology. Durham: Texto de Discussão da Duke University, 2002. Disponível em: HTTP://econ.duke.edu/uploads/assets/dje/2002/weiss.pdf Acesso em 22/07/2012.

WEINTRAUB, R. General equilibrium analysis. Cambridge: Cambridge University, 1985. 